Article

\title{
Synthesis and Self-Organization of Fluorene-Conjugated Bisimidazolylporphyrin and Its Optical Properties
}

\author{
Kazuya Ogawa $^{\dagger} *$, Naoyuki Makiuchi ${ }^{\ddagger}$ and Yoshiaki Kobuke ${ }^{\ddagger, \S}$
}

Graduate School of Materials Science, Nara Institute of Science and Technology, 8916-5 Takayama, Ikoma, Nara 630-0192, Japan; E-Mail: ma_naoyu@yahoo.co.jp (N.M.)

$\dagger$ Present address: Interdisciplinary Graduate School of Medicine and Engineering, Division of Medical and Engineering Science, Life Environment Medical Engineering, University of Yamanashi, 4-3-11 Takeda, Kofu, Yamanashi 400-8511, Japan.

* Present address: Institute of Advanced Energy, Kyoto University, Gokasho, Uji, Kyoto 611-0011, Japan; E-Mail: kobuke@iae.kyoto-u.ac.jp

$\S$ These authors contributed equally to this work.

* Author to whom correspondence should be addressed; E-Mail: kogawa@yamanashi.ac.jp; Tel./Fax: +81-55-220-8511.

Received: 26 November 2012; in revised form: 14 December 2012 / Accepted: 17 December 2012 / Published: 21 December 2012

\begin{abstract}
A conjugated-bisimidazolylporphyrin bridged by bis(ethynylfluorene) was synthesized and organized into linear polymer through self-coordination having mean molecular weights, $M_{\mathrm{w}}$ and $M_{\mathrm{n}}$, of $\sim 2.1 \times 10^{5} \mathrm{Da}$ and $\sim 1.6 \times 10^{5} \mathrm{Da}$, respectively. A large two-photon absorption cross section value of $3.4 \times 10^{5} \mathrm{GM}$ (per dimer unit) was observed. This value was comparable to that of the previously reported self-assembled linear polymer consisting of butadiyne-bridged imidazolylporphyrins. The two-photon absorption properties could be controlled by tuning the wavelength and absorption intensity of the one-photon absorption.
\end{abstract}

Keywords: porphyrin; self-assembly; two-photon absorption; fluorene; imidazole; Z-scan 


\section{Introduction}

Recently, much attention has been focused on organic dye molecules in view of optical applications such as organic solar cell [1], electronic luminescence [2], photon-mode optical memory using photochromic molecules [3], and nonlinear optics including two-photon absorption (2PA) materials [4-11]. Novel functions would be expected upon conjugation of two or more chromophores, even when a monomeric dye itself exhibits insignificant function. We developed two-photon absorption materials [12-22] using self-assembled multi-porphyrin arrays and found that the extension of the $\pi$-conjugation between the porphyrins with triple bonds was the most significant for 2PA enhancement. Complementary coordination of imidazolyl to zinc, in which the stability constant of the complementary dimer exceeded $10^{11} \mathrm{M}^{-1}$ in $\mathrm{CHCl}_{3}$ [23-25], also contributed to the enhancement. However, an additional expansion of $\pi$-conjugation gave rise to a large red-shift of the $\mathrm{S}_{0} \rightarrow \mathrm{S}_{1}$ one-photon absorption (1PA) to the two-photon resonance range (800 nm to $900 \mathrm{~nm})$ [22]. To prevent such an overlap of 2PA and 1PA, it is necessary to control the position of the $\mathrm{S}_{0} \rightarrow \mathrm{S}_{1}$ one-photon absorption by tuning the interaction between chromophores. Fluorene is a well-known $\pi$-spacer for two-photon absorption materials [26-33] and provides an angle of $160^{\circ}$ between two ethynylimidazolylporphyrins when these are connected at the 2- and 7-positions of fluorene (1). Therien and Anderson reported bisporphyrins bridged by a $\pi$-spacer comprising an acetylenic connection [5,34]. Compound $\mathbf{1}$ gave the linear polymer $\mathbf{1 P}$ by zinc-imidazolyl complementary coordination. Polymer $\mathbf{1 P}$ could easily be dissociated into the unit $\mathbf{1 M}$ by ligand coordination, such as with pyridine and imidazole. The slightly bent angle of $160^{\circ}$ was expected to reduce the exciton interaction between the two porphyrins and shift the 1PA bands to shorter wavelengths than those of the butadiyne-bridged bisimidazolylporphyrin array $\mathbf{2 P}$ without fluorene, allowing the measurement of the hidden 2PA bands in the shorter wavelength range. Similar fluorene-conjugated bisimidazolylporphyrins having two allyl groups at meso-positions have been synthesized to construct large macrocyclic arrays. The self-coordinated structures in the macrocycles were fixed by the ring-closing metathesis reaction of the allyl groups to investigate the effect of cyclization on 2PA by a femtosecond fluorescence method in the range between 800 and $875 \mathrm{~nm}$ [20]. Here, we report the synthesis of linear polymers self-organized by fluorene-conjugated bisimidazolylporphyrins without allyl groups, and their 2PA properties in the range from 740 to $930 \mathrm{~nm}$.

\section{Results and Discussion}

\subsection{Synthesis}

Bisporphyrin $\mathbf{1}$ was synthesized from 5,15-bis(2-methoxycarbonylethyl)-10(trimethylsilylpropargyl)-20-(1-methyl-2-imidazolyl)porphyrinatozinc 3 [15] and 2,7-diiodo-9,9bis(3,5,5-trimethylhexyl)fluorene 4 [35,36] using a $\mathrm{Pd}_{2}(\mathrm{dba})_{3} / \mathrm{AsPh}_{3}$ catalytic system, where deprotection of the TMS group and the coupling reaction were conducted in a one-pot procedure because of the low solubility of the deprotected ethynylimidazolylporphyrin (Scheme 1). Purification by preparative gel permeation chromatography (GPC) with pyridine elution allowed for the isolation of 1 from the crude mixture in 33\% yield. Both the MALDI-TOF mass spectral and analytical GPC measurements showed a single species corresponding to the molecular weight of $\mathbf{1}$. However, broad 
signals were obtained in the NMR spectrum of $\mathbf{1}$, even in a coordinating solvent such as pyridine- $d_{5}$. Accordingly, the free base 5 was prepared by treatment with $\mathrm{HCl}$ to obtain a clearer NMR spectrum (Figure 1). Bisporphyrin 1 could not be obtained when 2,7-dibromofluorene was used as a starting material, due to its low reactivity.

Scheme 1. Self-assembled imidazolylporphyrins connected by triple bond.

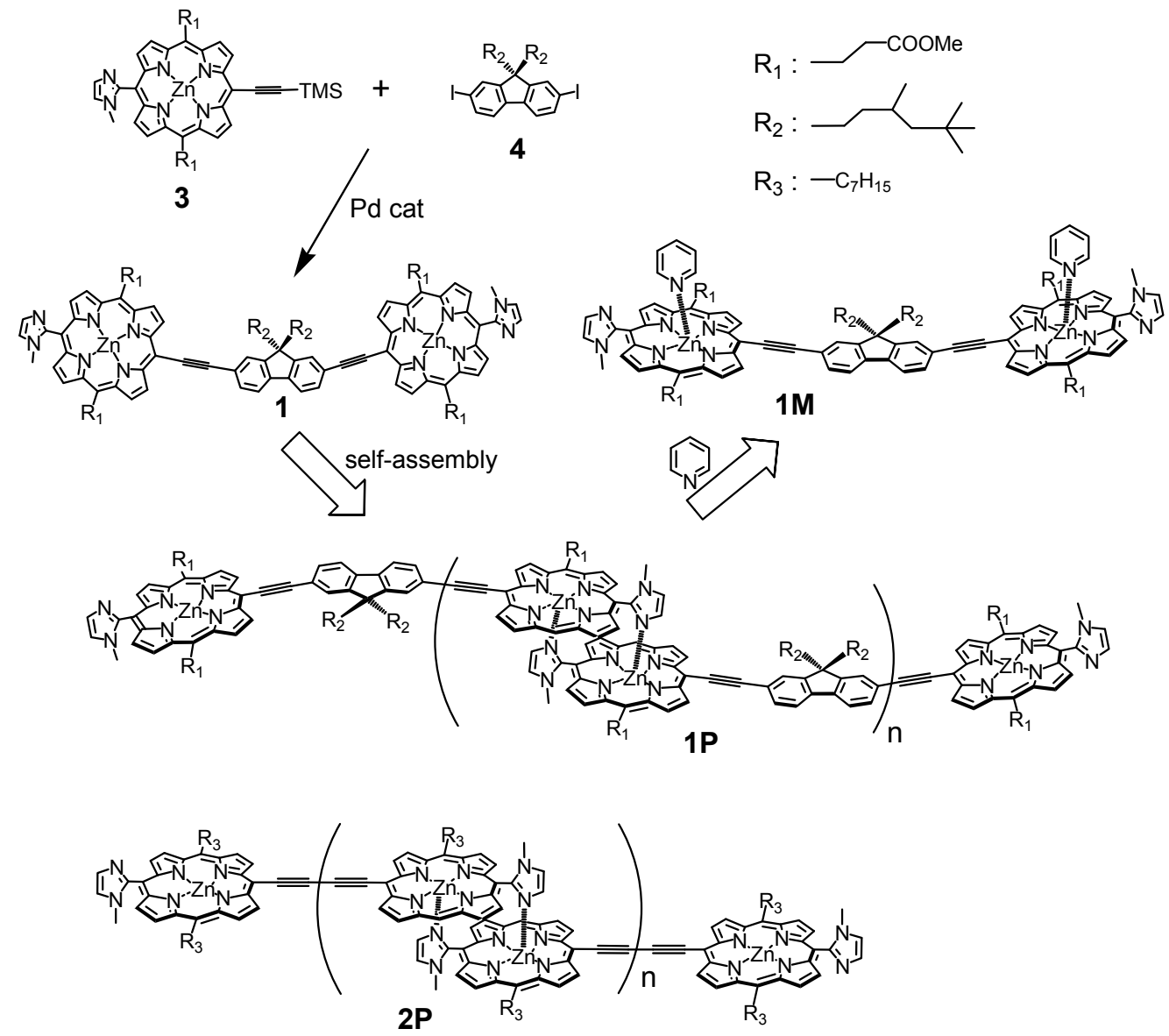

Figure 1. $600 \mathrm{MHz}{ }^{1} \mathrm{H}$ NMR spectrum of free base 5 in $\mathrm{CDCl}_{3}$.

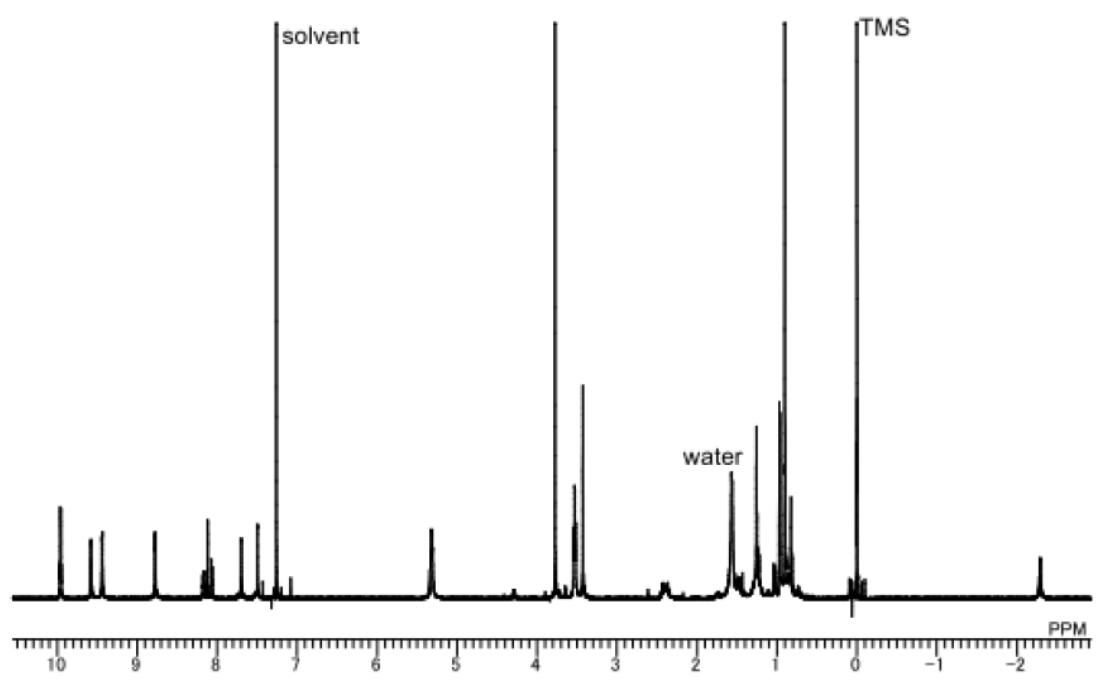




\subsection{Formation of Self-Assembled Polymer}

When 1 was dissolved in a nonpolar solvent such as chloroform or 1,1,2,2,-tetrachloroethane after the evaporation of pyridine, the long linear polymer $\mathbf{1 P}$ was formed by self-coordination. Polymer 1P changed gradually to cyclic arrays of various sizes in chloroform above $45{ }^{\circ} \mathrm{C}$ or in chloroform/methanol $(7: 3, v / v \%)$ at room temperature. Such cyclic arrays have been reported elsewhere [20]. 1P retains its linear polymer structure in chloroform or in tetrachloroethane without methanol at room temperature sufficiently long for 2PA measurements. The molecular weight of 1P was analyzed by GPC with chloroform elution on a column with an exclusion limit of $5 \times 10^{5} \mathrm{Da}$. Figure 2 shows the GPC chart of 1P monitored at $420 \mathrm{~nm}$ by an UV-vis photodiode array. The arrows indicate the peak positions of polystyrene standards. The absorption spectra of $\mathbf{1 P}$ at different retention times between 7 and 10 min were identical. The distribution maximum of the elution curve of $\mathbf{1 P}$ appeared around Mw $1.5 \times 10^{5} \mathrm{Da}$. The mean molecular weights, $M_{\mathrm{w}}$ and $M_{\mathrm{n}}$, estimated by comparing the data with those of polystyrene standards [37], were $\sim 2.1 \times 10^{5} \mathrm{Da}$ and $\sim 1.6 \times 10^{5} \mathrm{Da}$, respectively, which results in a polydispersity index of $M_{\mathrm{w}} / M_{\mathrm{n}}=1.4$. The mean molecular weight of $M_{\mathrm{n}}=1.6 \times 10^{5}$ corresponded to ca. 94 units of $\mathbf{1}$, and these values were comparable with linear self-assembled bisporphyrin arrays [14].

Figure 2. GPC chart of 1 P along with the peak positions of polystyrene standards.

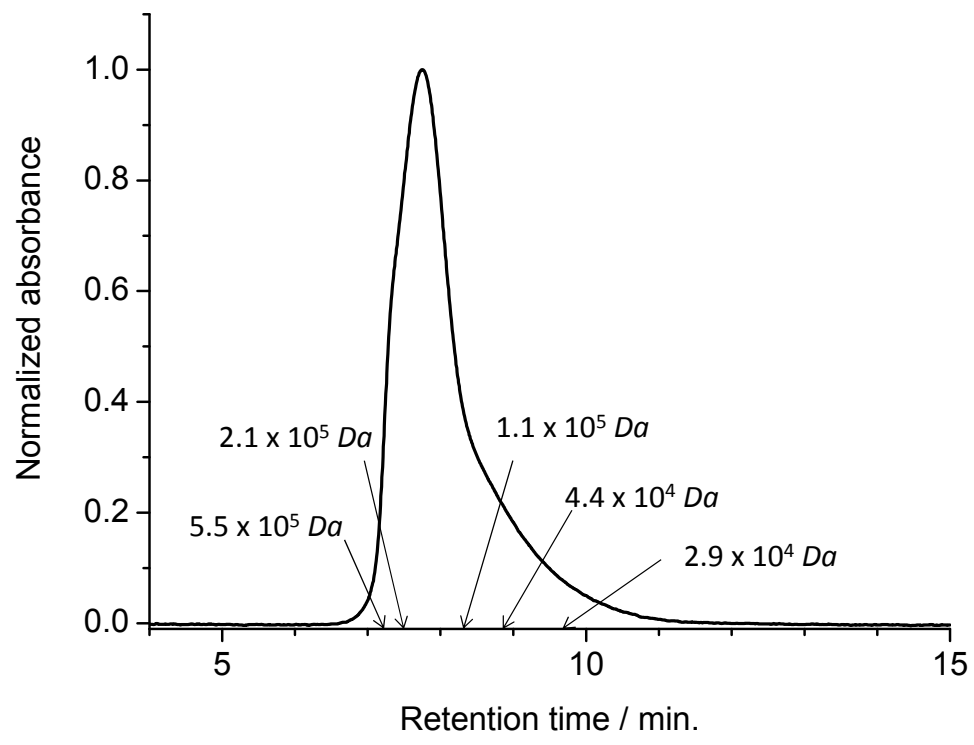

\subsection{UV-Vis Absorption Spectra}

The UV-vis absorption spectra of $\mathbf{1 P}$ in tetrachloroethane (solid line), $\mathbf{1 M}$ in tetrachloroethane/pyridine $(7: 3, v / v \%)$, and $\mathbf{2 P}$ in chloroform (dashed line) are shown in Figure 3. The Soret and Q-bands of 1P were observed at around 485 and $670 \mathrm{~nm}$, respectively. These were blue-shifted by 15 and $70 \mathrm{~nm}$ compared with those of $2 \mathbf{P}(500 \mathrm{~nm}$ and $740 \mathrm{~nm})$, suggesting a decrease in interaction due to the long distance and torsional angle of $160^{\circ}$ between the two porphyrins. However, the absorption intensity of the Q-band in 1P was still strong. On the other hand, the Q-band of unit $1 \mathrm{M}$ was blue-shifted to $655 \mathrm{~nm}$ and its intensity was considerably decreased because of the disappearance of excitonic interactions through the zinc-imidazolyl complementary coordination. 
Figure 3. One-photon absorption spectra of $\mathbf{1 P}$ (bold line) in tetrachloroethane, $\mathbf{1 M}$ (thin line) in tetrachloroethane/pyridine $(7: 3, v / v)$, and $\mathbf{2} \mathbf{P}$ (dashed line) in $\mathrm{CHCl}_{3}$.

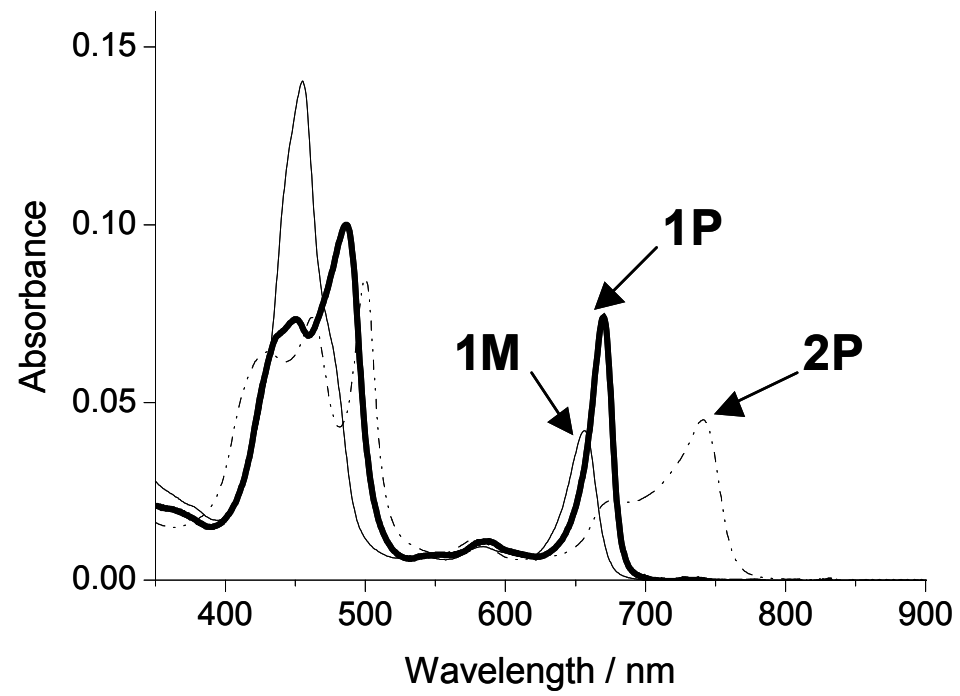

\subsection{Nonlinear Absorption}

The 2PA cross sections of $1 \mathbf{P}$ and $\mathbf{1 M}$ were measured with an open-aperture $\mathrm{Z}$-scan technique at wavelengths from 740 to $920 \mathrm{~nm}$, using a Nd:YAG nanosecond pulse laser system with optical parametric oscillator. The nanosecond measurement system and analysis method were previously reported [14]. In general, the effective cross section value, ${ }^{\text {eff }} \sigma^{(2)}$, measured using nanosecond pulses, is 2-3 orders of magnitude larger than the pure 2PA cross section, $\sigma^{(2)}$, obtained with femtosecond pulses, because the excited state absorption (ESA) contributes to the data. In our porphyrin systems, the ${ }^{\text {eff }} \sigma^{(2)}$ values were 30 to 50 times larger than the $\sigma^{(2)}$ values, and the 2PA spectra measured with nanosecond and femtosecond pulses were similar. Therefore, ${ }^{\text {eff }} \sigma^{(2)}$ values obtained by nanosecond measurements were a good measure for the 2PA properties. Moreover, in some 2PA applications, such as 2PA-PDT and 3-D optical memory, nanosecond pulses will be more appropriate because of the ease of operation and availability.

Figure 4 shows typical Z-scan traces for 1P in tetrachloroethane (dotted trace) and theoretically fitted curves (solid line) at $890 \mathrm{~nm}$ ((a) at a concentration of $7.66 \times 10^{-5} \mathrm{M}$ with a pulse energy of $1.6 \mathrm{~mJ})$ and $760 \mathrm{~nm}\left((\mathrm{~b})\right.$ at a concentration of $6.87 \times 10^{-5} \mathrm{M}$ with a pulse energy of $\left.1.45 \mathrm{~mJ}\right)$. The ${ }^{\text {eff }} \sigma^{(2)}$ values were obtained from the fitted curves and theoretical equations [14,38]. Figure 5 shows 2PA spectra of 1P (square). Two peaks were observed at 760 and $890 \mathrm{~nm}$ with large ${ }^{\text {eff }} \sigma^{(2)}$ values of $3.4 \times 10^{5}$ and $1.1 \times 10^{5} \mathrm{GM}$ (per dimer unit), respectively. 2PA spectra of $\mathbf{1 M}$ (Figure 5, cross) also showed two peaks at 770 and $890 \mathrm{~nm}$, with values of $9.1 \times 10^{4}$ and $5.6 \times 10^{4} \mathrm{GM}$, respectively. The values obtained for $\mathbf{1 M}$ were almost one-third to one-half of those of 1P. As described for the absorption spectra, 1P showed strong one-photon absorption of the Q-band at $670 \mathrm{~nm}$. On the other hand, that of $\mathbf{1 M}$ was blue-shifted to $655 \mathrm{~nm}$ and the oscillator strength was almost half that of 1P, indicating that the resonance enhancement for $\mathbf{1 M}$, which comes from the one-photon absorption near the two-photon resonance [38,39], would be expected to be poorer than that for 1P. This may clearly explain the difference in the ${ }^{\text {eff }} \sigma^{(2)}$ values between $\mathbf{1 P}$ and $\mathbf{1 M}$, and we can confirm again that self-organization through complementary coordination is effective for the enhancement $[13,14]$. The 
shapes of the 2PA spectra of $\mathbf{1 P}$ and $\mathbf{1 M}$ were similar, but did not correspond to those of the one-photon spectra in the wavelength range of half of 2PA, i.e., $370 \mathrm{~nm}$ to $500 \mathrm{~nm}$, suggesting that the final state by $2 \mathrm{PA}$ is different from the one-photon excited state $[5,39]$. The ${ }^{\text {eff }} \sigma^{(2)}$ values per dimer unit of $1 P$ in the wavelength range between 800 and $860 \mathrm{~nm}$ ranged from $3.9 \times 10^{4}$ to $5.4 \times 10^{4} \mathrm{GM}$. These values were similar to those of macrocycles measured by femtosecond pulses [20], indicating negligible ESA contributions in this wavelength range, considering nanosecond measurement.

Figure 4. Typical open-aperture Z-scan traces for $\mathbf{1 P}$ (dotted trace) and theoretically fitted curves (solid line) at $890 \mathrm{~nm}$ (a at a concentration of $7.66 \times 10^{-5} \mathrm{M}$ in 1,1,2,2,-tetrachloroethane with a pulse energy of $1.6 \mathrm{~mJ})$ and $760 \mathrm{~nm}(\mathbf{b}$ at a concentration of $6.87 \times 10^{-5} \mathrm{M}$ in 1,1,2,2,-tetrachloroethane with a pulse energy of $1.45 \mathrm{~mJ}$ ).
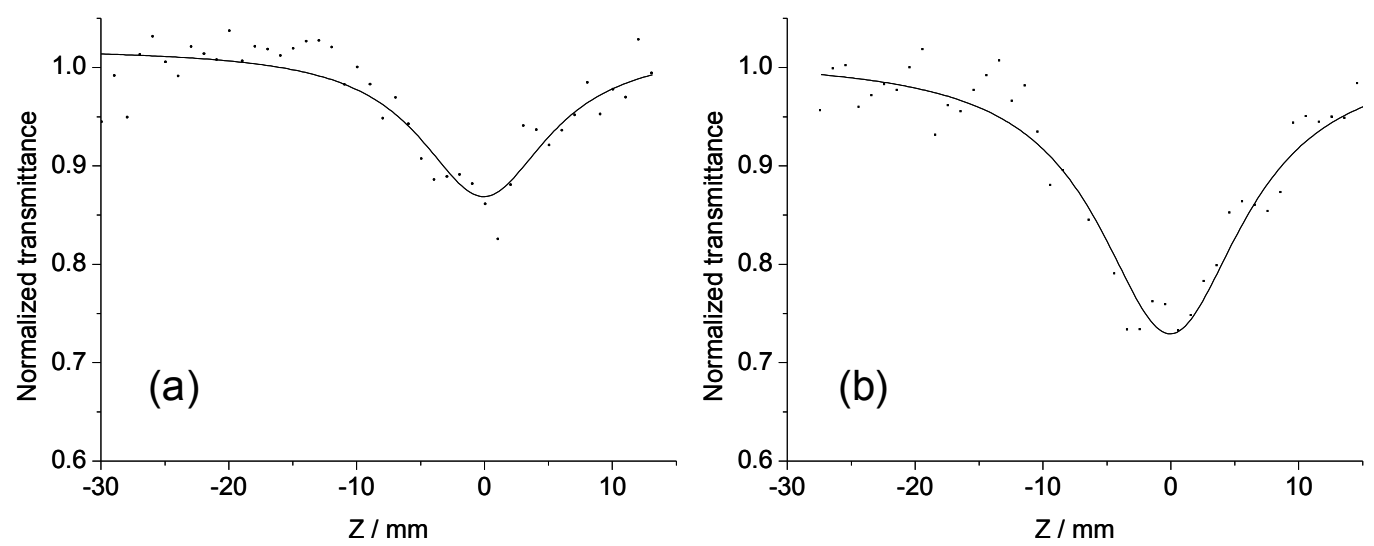

Figure 5. 2PA spectra of $\mathbf{1 P}(\mathbf{\square}), \mathbf{1 M}(\times)$, and $\mathbf{2 P}(+)$.

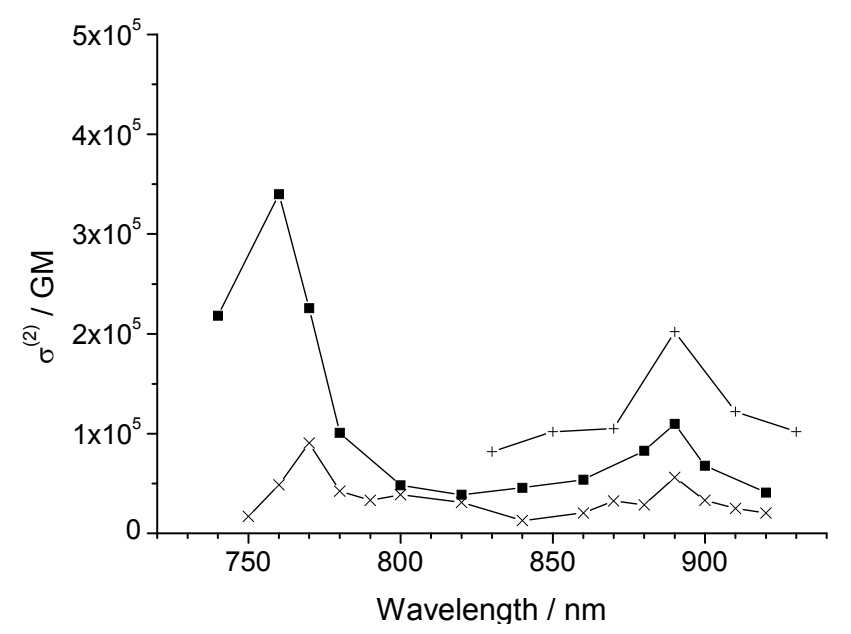

In the previous report, the linear polymer 2P exhibited a large ${ }^{\text {eff }} \sigma^{(2)}$ value of $2.0 \times 10^{5} \mathrm{GM}$ (per dimer unit) at $890 \mathrm{~nm}$ [14], which was twice of that of $\mathbf{1 P}$ at the same wavelength. $\mathbf{2} \mathbf{P}$ had a strong one-photon absorption of the Q-band at $740 \mathrm{~nm}$ that was longer than $\mathbf{1 P}$ by $70 \mathrm{~nm}$, suggesting that $\mathbf{2 P}$ undergoes a stronger resonance enhancement effect than 1P. However, the shift of the strong Q-band to the shorter wavelength of $670 \mathrm{~nm}$ for $1 P$ allows the Z-scan measurements in the wavelength range of 720 to $820 \mathrm{~nm}$, which is prohibited by one-photon absorption in the case of $\mathbf{2 P}$. Then, we could find another strong 2PA band at around $760 \mathrm{~nm}$ with the largest ${ }^{\text {eff }} \sigma^{(2)}$ value of $3.4 \times 10^{5} \mathrm{GM}$. The cross sections increased with the shortening of the incident light wavelength below around $800 \mathrm{~nm}$. Similar 
behavior was observed in simple porphyrins such as tetraphenylporphyrin, Zn octaethylporphyrin, and a self-assembled dimer measured using a femtosecond fluorescence method [39] or nanosecond Z-scan method [16]. This has been explained as a resonance enhancement near the one-photon absorption of the Q-band.

\section{Experimental Section}

\section{General}

${ }^{1} \mathrm{H}$ NMR spectra were obtained in $\mathrm{CDCl}_{3}$ with $\mathrm{Me}_{4} \mathrm{Si}$ as the internal standard $(\delta 0 \mathrm{ppm})$ and recorded on either a JEOL JNM EX270 or JEOL ECP600. UV-vis spectra were obtained on either a Shimadzu UV-1650PC or UV-3100PC. MALDI-TOF mass spectra were obtained on Perseptive Biosystems Voyager DE-STR and Shimadzu/KRATOS Axima-CFR Kompact MALDI with dithranol (Aldrich, St. Louis, MO, USA) or 2-[3-(4-tert-butylphenyl)-2-methylprop-2-enylidene]-malononitrile (DCTB, Aldrich) as the matrix. Reactions were monitored on silica gel 60 F254 TLC plates (Merck, Darmstadt, Germany). The silica gel utilized for column chromatography was purchased from Kanto Chemical Co. Inc.: Silica Gel 60N (Spherical, Neutral) 60-210 mm and 40-50 mm (Flash). The alumina used for column chromatography was purchased from Merck: Aluminum oxide 90 active basic. Analytical GPC measurements were performed on a HEWLETT PACKARD 1100 SERIES with a JAIGEL $3 \mathrm{H}-\mathrm{A}$ or $4 \mathrm{H}-\mathrm{A}$ column for chloroform eluent. The nanosecond Z-scan measurement system and analysis method were previously reported [14].

Synthesis of 1: Under argon atmosphere, 3 [15] (95 mg, $132 \mu \mathrm{mol})$ and 4 [35,36] (35.4 mg, $52.6 \mu \mathrm{mol})$ were dissolved in dry THF $(45 \mathrm{~mL})$. Then, tetrabutylammonium fluoride in THF $(264 \mu \mathrm{L}$, $264 \mu \mathrm{mol})$ was added. After $30 \mathrm{~min}$, triethylamine $(9 \mathrm{~mL}), \mathrm{Pd}_{2}(\mathrm{dba})_{3}(27.2 \mathrm{mg}, 26.3 \mu \mathrm{mol})$, and $\mathrm{AsPh}_{3}$ (32.2 $\mathrm{mg}, 105 \mu \mathrm{mol}$ ) were added. After stirring $4 \mathrm{~h}$, the reaction solvents were evaporated. The residue was dissolved in chloroform and washed with water. The crude residue after concentration was purified by preparative GPC (Tosoh $\mathrm{G} 2500 \mathrm{H}_{\mathrm{HR}}$, pyridine elution) to give 1 (29 $\mathrm{mg}, 33 \%$ ). MALDI-TOF mass (dithranol) $m / z 1711.66(\mathrm{M}+\mathrm{H})^{+}$, calcd for $\mathrm{C}_{99} \mathrm{H}_{98} \mathrm{~N}_{12} \mathrm{O}_{8} \mathrm{Zn}_{2}, 1710.62$; UV-vis $\lambda_{\max }\left(\mathrm{nm}\right.$, in $\left.\mathrm{CHCl}_{3}\right) 449,484,583,667$; fluorescence $\lambda_{\max }\left(\mathrm{nm}, \lambda_{\mathrm{ex}}=484 \mathrm{~nm}\right.$, in $\left.\mathrm{CHCl}_{3}\right) 670,731$.

Synthesis of 5: Under an Ar atmosphere, $1(4.5 \mathrm{mg}, 2.63 \mu \mathrm{mol})$ in chloroform $(30 \mathrm{~mL})$ was added into a mixture of $12 \mathrm{~N}$ hydrochloric acid $(8 \mathrm{~mL})$ and methanol $(40 \mathrm{~mL})$. After stirring for $30 \mathrm{~min}$ at room temperature, the reaction solution was diluted with water and extracted with chloroform. The chloroform layer was washed with saturated $\mathrm{NaHCO}_{3}$ aqueous solution. The crude residue after concentration was purified with silica gel column chromatography $\left(\mathrm{CHCl}_{3} / \mathrm{MeOH}=20 / 1\right)$ (yield: 53\%). ${ }^{1} \mathrm{H}$ NMR (600 MHz, $\mathrm{CDCl}_{3}$ ) $\delta 9.96$ (q, 4H, $\left.J=4.8 \mathrm{~Hz}, \beta\right), 9.58$ (q, 4H, $J=4.8 \mathrm{~Hz}, \beta$ ), $9.44(\mathrm{~d}, 4 \mathrm{H}, J=4.8 \mathrm{~Hz}, \beta), 8.78(\mathrm{~d}, 4 \mathrm{H}, J=4.8 \mathrm{~Hz}, \beta), 8.17(\mathrm{~m}, 2 \mathrm{H}, \mathrm{Ph}), 8.12(\mathrm{~s}, 2 \mathrm{H}, \mathrm{Ph}), 8.07$ (d, 2H, $J=7.8 \mathrm{~Hz}, \mathrm{Ph}), 7.70(\mathrm{~d}, 1 \mathrm{H}, J=1.8 \mathrm{~Hz}, \mathrm{im}), 7.50(\mathrm{~d}, 1 \mathrm{H}, J=1.8 \mathrm{~Hz}, \mathrm{im}), 5.32(\mathrm{t}, 8 \mathrm{H}, J=7.8 \mathrm{~Hz}$, $\mathrm{CH}_{2}$ ), 3.77 (s, 12H, $J=7.8 \mathrm{~Hz}, \mathrm{OMe}$ ), 3.53 (t, 8H, $J=7.8 \mathrm{~Hz}, \mathrm{CH}_{2}$ ), 3.43 (s, 6H, NMe), 2.36-0.81 $(\mathrm{m}, 38 \mathrm{H}$, alkyl groups in fluorene), $-2.29(\mathrm{~s}, 4 \mathrm{H}, \mathrm{NH})$; MALDI-TOF mass (dithranol), $\mathrm{m} / \mathrm{z} 1587.75$ $(\mathrm{M}+\mathrm{H})^{+}$, calcd for $\mathrm{C}_{99} \mathrm{H}_{102} \mathrm{~N}_{12} \mathrm{O}_{8}, 1586.79$. 


\section{Conclusions}

In conclusion, a porphyrin-fluorene conjugate connected by triple bonds $\mathbf{1}$ was successfully synthesized through a Pd-catalyzed coupling reaction. Polymer 1P, self-assembled through zinc-imidazolyl complementary coordination, was successfully formed. The 2PA properties could be controlled by tuning the wavelength and absorption intensity of 1PA bands, which were altered by changing the interactions between the porphyrins by the introduction of fluorene or complementary coordination.

\section{Acknowledgments}

We gratefully acknowledge financial support through Grants-in-Aid for Scientific Research (A) (No. 15205020) and Young Scientists (B) (No. 18750118) (Kazuya Ogawa) from the Ministry of Education, Culture, Sports, Science, and Technology, Japan (Monbu Kagakusho).

\section{References}

1. Gunes, S.; Neugebauer, H.; Sariciftci, N.S. Conjugated polymer-based organic solar cells. Chem. Rev. 2007, 107, 1324-1338.

2. Grimsdale, A.C.; Chan, K.L.; Martin, R.E.; Jokisz, P.G.; Holmes, A.B. Synthesis of light-emitting conjugated polymers for applications in electroluminescent devices. Chem. Rev. 2009, 109, 897-1091.

3. Irie, M. Photochromism: Memories and switches-Introduction. Chem. Rev. 2000, 100, 1683-1683.

4. Drobizhev, M.; Stepanenko, Y.; Rebane, A.; Wilson, C.J.; Screen, T.E.O.; Anderson, H.L. Strong cooperative enhancement of two-photon absorption in double-strand conjugated porphyrin ladder arrays. J. Am. Chem. Soc. 2006, 128, 12432-12433.

5. Drobizhev, M.; Stepanenko, Y.; Dzenis, Y.; Karotki, A.; Rebane, A.; Taylor, P.N.; Anderson, H.L. Understanding strong two-photon absorption in pi-conjugated porphyrin dimers via double-resonance enhancement in a three-level model. J. Am. Chem. Soc. 2004, 126, 15352-15353.

6. Hisaki, I.; Hiroto, S.; Kim, K.S.; Noh, S.B.; Kim, D.; Shinokubo, H.; Osuka, A. Synthesis of doubly beta-to-beta 1,3-butadiyne-bridged diporphyrins: Enforced planar structures and large two-photon absorption cross sections. Angew. Chem. Int. Ed. 2007, 46, 5125-5128.

7. Ikeda, C.; Yoon, Z.S.; Park, M.; Inoue, H.; Kim, D.; Osuka, A. Helicity induction and two-photon absorbance enhancement in zinc(ii) meso-meso linked porphyrin oligomers via intermolecular hydrogen bonding interactions. J. Am. Chem. Soc. 2005, 127, 534-535.

8. Bhaskar, A.; Guda, R.; Haley, M.M.; Goodson, T. Building symmetric two-dimensional two-photon materials. J. Am. Chem. Soc. 2006, 128, 13972-13973.

9. Bhaskar, A.; Ramakrishna, G.; Lu, Z.K.; Twieg, R.; Hales, J.M.; Hagan, D.J.; van Stryland, E.; Goodson, T. Investigation of two-photon absorption properties in branched alkene and alkyne chromophores. J. Am. Chem. Soc. 2006, 128, 11840-11849.

10. Arnbjerg, J.; Jimenez-Banzo, A.; Paterson, M.J.; Nonell, S.; Borrell, J.I.; Christiansen, O.; Ogilby, P.R. Two-photon absorption in tetraphenylporphycenes: Are porphycenes better candidates than porphyrins for providing optimal optical properties for two-photon photodynamic therapy. J. Am. Chem. Soc. 2007, 129, 5188-5199. 
11. Kamada, K.; Ohta, K.; Kubo, T.; Shimizu, A.; Morita, Y.; Nakasuji, K.; Kishi, R.; Ohta, S.; Furukawa, S.; Takahashi, H.; et al. Strong two-photon absorption of singlet diradical hydrocarbons. Angew. Chem. Int. Ed. 2007, 46, 3544-3546.

12. Ogawa, K.; Zhang, T.Q.; Yoshihara, K.; Kobuke, Y. Large third-order optical nonlinearity of self-assembled porphyrin oligomers. J. Am. Chem. Soc. 2002, 124, 22-23.

13. Ogawa, K.; Ohashi, A.; Kobuke, Y.; Kamada, K.; Ohta, K. Strong two-photon absorption of self-assembled butadiyne-linked bisporphyrin. J. Am. Chem. Soc. 2003, 125, 13356-13357.

14. Ogawa, K.; Ohashi, A.; Kobuke, Y.; Kamada, K.; Ohta, K. Two-photon absorption properties of self-assemblies of butadiyne-linked bis(imidazolylporphyrin). J. Phys. Chem. B 2005, 109, 22003-22012.

15. Ogawa, K.; Hasegawa, H.; Inaba, Y.; Kobuke, Y.; Inouye, H.; Kanemitsu, Y.; Kohno, E.; Hirano, T.; Ogura, S.; Okura, I. Water-soluble bis(imidazolylporphyrin) self-assemblies with large two-photon absorption cross sections as potential agents for photodynamic therapy. J. Med. Chem. 2006, 49, 2276-2283.

16. Tanihara, J.; Ogawa, K.; Kobuke, Y. Two-photon absorption properties of conjugated supramolecular porphyrins with electron donor and acceptor. J. Photochem. Photobiol. A 2006, $178,140-149$.

17. Dy, J.T.; Ogawa, K.; Satake, A.; Ishizumi, A.; Kobuke, Y. Water-soluble self-assembled butadiyne-bridged bisporphyrin: A potential two-photon-absorbing photosensitizer for photodynamic therapy. Chem. Eur. J. 2007, 13, 3491-3500.

18. Dy, J.T.; Maeda, R.; Nagatsuka, Y.; Ogawa, K.; Kamada, K.; Ohta, K.; Kobuke, Y. A photochromic porphyrin-perinaphthothioindigo conjugate and its two-photon absorption properties. Chem. Commun. 2007, 5170-5172.

19. Dy, J.; Ogawa, K.; Kamada, K.; Ohta, K.; Kobuke, Y. Stepwise elongation effect on the two-photon absorption of self-assembled butadiyne porphyrins. Chem. Commun. 2008, 3411-3413.

20. Raymond, J.E.; Bhaskar, A.; Goodson, T.; Makiuchi, N.; Ogawa, K.; Kobuke, Y. Synthesis and two-photon absorption enhancement of porphyrin macrocycles. J. Am. Chem. Soc. 2008, 130, $17212-17213$.

21. Morisue, M.; Ogawa, K.; Kamada, K.; Ohta, K.; Kobuke, Y. Strong two-photon and three-photon absorptions in the antiparallel dimer of a porphyrin-phthalocyanine tandem. Chem. Commun. 2010, 46, 2121-2123.

22. Kamada, K.; Hara, C.; Ogawa, K.; Ohta, K.; Kobuke, Y. Strong two-photon absorption and its saturation of a self-organized dimer of an ethynylene-linked porphyrin tandem. Chem. Commun. 2012, 48, 7988-7990.

23. Kobuke, Y.; Miyaji, H. Supramolecular organization of imidazolyl-porphyrin to a slipped cofacial dimer. J. Am. Chem. Soc. 1994, 116, 4111-4112.

24. Kobuke, Y.; Ogawa, K. Porphyrin supramolecules for artificial photosynthesis and molecular photonic/electronic materials. Bull. Chem. Soc. Jpn. 2003, 76, 689-708.

25. Ogawa, K.; Kobuke, Y. Formation of a giant supramolecular porphyrin array by self-coordination. Angew. Chem. Int. Ed. 2000, 39, 4070-4073. 
26. Rogers, J.E.; Slagle, J.E.; McLean, D.G.; Sutherland, R.L.; Brant, M.C.; Heinrichs, J.; Jakubiak, R.; Kannan, R.; Tan, L.S.; Fleitz, P.A. Insight into the nonlinear absorbance of two related series of two-photon absorbing chromophores. J. Phys. Chem. A 2007, 111, 1899-1906.

27. Morales, A.R.; Belfield, K.D.; Hales, J.M.; Van Stryland, E.W.; Hagan, D.J. Synthesis of two-photon absorbing unsymmetrical fluorenyl-based chromophores. Chem. Mater. 2006, 18, 4972-4980.

28. Padmawar, P.A.; Rogers, J.E.; He, G.S.; Chiang, L.Y.; Tan, L.S.; Canteenwala, T.; Zheng, Q.D.; Slagle, J.E.; McLean, D.G.; Fleitz, P.A.; et al. Large cross-section enhancement and intramolecular energy transfer upon multiphoton absorption of hindered diphenylaminofluorene-c-60 dyads and triads. Chem. Mater. 2006, 18, 4065-4074.

29. Zheng, Q.D.; He, G.S.; Prasad, P.N. Pi-conjugated dendritic nanosized chromophore with enhanced two-photon absorption. Chem. Mater. 2005, 17, 6004-6011.

30. Belfield, K.D.; Morales, A.R.; Kang, B.S.; Hales, J.M.; Hagan, D.J.; van Stryland, E.W.; Chapela, V.M.; Percino, J. Synthesis, characterization, and optical properties of new two-photon-absorbing fluorene derivatives. Chem. Mater. 2004, 16, 4634-4641.

31. Belfield, K.D.; Hagan, D.J.; van Stryland, E.W.; Schafer, K.J.; Negres, R.A. New two-photon absorbing fluorene derivatives: Synthesis and nonlinear optical characterization. Org. Lett. 1999, $1,1575-1578$.

32. Reinhardt, B.A.; Brott, L.L.; Clarson, S.J.; Dillard, A.G.; Bhatt, J.C.; Kannan, R.; Yuan, L.X.; He, G.S.; Prasad, P.N. Highly active two-photon dyes: Design, synthesis, and characterization toward application. Chem. Mater. 1998, 10, 1863-1874.

33. Yao, S.; Belfield, K.D. Synthesis of two-photon absorbing unsymmetrical branched chromophores through direct tris(bromomethylation) of fluorene. J. Org. Chem. 2005, 70, 5126-5132.

34. Susumu, K.; Duncan, T.V.; Therien, M.J. Potentiometric, electronic structural, and ground- and excited-state optical properties of conjugated bis[(porphinato)zinc(ii)] compounds featuring proquinoidal spacer units. J. Am. Chem. Soc. 2005, 127, 5186-5195.

35. Lee, S.H.; Nakamura, T.; Tsutsui, T. Synthesis and characterization of oligo(9,9-dihexyl-2,7-fluorene ethynylene)s: For application as blue light-emitting diode. Org. Lett. 2001, 3, 2005-2007.

36. Kannan, R.; He, G.S.; Lin, T.C.; Prasad, P.N.; Vaia, R.A.; Tan, L.S. Toward highly active two-photon absorbing liquids. Synthesis and characterization of 1,3,5-triazine-based octupolar molecules. Chem. Mater. 2004, 16, 185-194.

37. Balke, S.T.; Hamielec, A.E.; LeClair, B.P.; Pearce, S.L. Gel permeation chromatography. Ind. Eng. Chem. Prod. Res. Dev. 1969, 8, 54-57.

38. Kamada, K.; Ohta, K.; Yoichiro, I.; Kondo, K. Two-photon absorption properties of symmetric substituted diacetylene: Drastic enhancement of the cross section near the one-photon absorption peak. Chem. Phys. Lett. 2003, 372, 386-393.

39. Drobizhev, M.; Karotki, A.; Kruk, M.; Rebane, A. Resonance enhancement of two-photon absorption in porphyrins. Chem. Phys. Lett. 2002, 355, 175-182.

(C) 2013 by the authors; licensee MDPI, Basel, Switzerland. This article is an open access article distributed under the terms and conditions of the Creative Commons Attribution license (http://creativecommons.org/licenses/by/3.0/). 